\title{
How to Enforce Presenteeism with ICT while Mitigating Technostress - A Case Study
}

\author{
Roni Luoma \\ Aalto University \\ School of Business \\ roni.luoma@aalto.fi
}

\author{
Esko Penttinen \\ Aalto University \\ School of Business \\ esko.penttinen@aalto.fi
}

\author{
Tapani Rinta-Kahila \\ The University of Queensland \\ UQ Business School \& AIBE \\ t.rintakahila@uq.edu.au
}

\begin{abstract}
We study enforced presenteeism, a source of technostress in which individuals are involuntarily exposed to stimuli from electronic connectivity systems. Drawing on a case study where enforced presenteeism is introduced in the form of a new contact center enterprise software, we analyze bank employees' technostress before and after a process change that involves implementing a presenteeism-enabling information and communication technology (ICT). We find that prior to the change, employees exhibit high levels of technostress stemming from expected increases in work overload, invasion of privacy, and information overload. However, against all expectations, the employees' stress levels decrease as a result of the implementation as specific ICT affordances are leveraged in a way that gives employees increased control over their work, increases transparency, and empowers them. We provide theoretical and practical implications for our findings.
\end{abstract}

\section{Introduction}

In the information systems (IS) literature on technostress, presenteeism" is defined as "the degree to which technologies enable individuals to be reachable" [2, p. 837]. While most instances of presenteeism revolve around voluntary presenteeism (i.e., we somewhat voluntarily expose ourselves to the omnipresence of mobile phones and other connectivity devices, e.g., [22, 34]), sometimes presenteeism is enforced upon individuals and thus involuntary in nature. For example, an organization might enforce

\footnotetext{
${ }^{1}$ We acknowledge that the term presenteeism has different connotations; for example, in the organizational behavior literature it is juxtaposed with absenteeism and refers to attending work while ill [17]. We, naturally, employ the term in the IS meaning given above.
}

their employees to be constantly reachable through a certain enterprise information system [31, 44].

Information and communication technologies (ICTs) are changing the ways in which organizations create and capture value, how and where employees work as well as how interaction and communication among employees happens [7]. People who become enabled by technology should perceive various positive reactions such as improved productivity and job satisfaction, but if the technology causes oppression it may lead to stress, demotivation or counterproductive behaviors [2, 14, 41]. From the change success perspective, understanding negative cognitive responses is of paramount importance as it enables organizations to prevent or diminish the disruptive effects of such responses.

While most of IS literature has been concerned with the instrumental objectives of ICT deployment, such as higher efficiency and profitability, Sarker et al. [35] have called for researchers to give more attention to the humanistic outcomes of technology deployment, including those of job satisfaction and employee wellbeing. ICT-enabled presenteeism can arguably increase an organization's internal efficiency through more fluid interaction among employees and managers, and it can also be leveraged to enhance the organization's reachability to their external stakeholders such as customers.

Yet, presenteeism is a major factor contributing to technostress [10,43]. Constant reachability has been shown to cause the emergence of stressors such as invasion of privacy, work overload, and role ambiguity, which in turn contribute to experienced strain [2]. Especially in organizational context, where presenteeism can be enforced upon employees, the stressors' ill effects may accentuate because employees have less mechanisms to cope with those effects, as compared to private ICT use contexts where presenteeism is voluntary. The extent of real-time connectivity and reachability at workplace has escalated in recent decades, suggesting that the 
significance of presenteeism as a source of technostress is growingly significant $[5,18,23]$.

Technostress has been found to result in workers' diminished job satisfaction, productivity, and organizational commitment $[31,43]$. Therefore, ICTenabled presenteeism appears to entail inherent tensions between the instrumental and humanistic outcomes of ICT implementation. Although presenteeism can yield efficiency gains, too much of it results in technostress, which not only contradicts with ICT's humanistic outcomes but ultimately jeopardizes the instrumental ones, too. Managers are then faced with a challenge to jointly optimize the two objectives without sacrificing too much on either front [18]. Yet, existing studies on presenteeism and technostress have not explored this tension and its potentially resulting tradeoffs. Against this backdrop, we ask: how to effectively deploy ICT-enabled presenteeism in a way that mitigates technostress?

To respond to this question, we conducted an indepth case study in a Finnish bank that rolled out a new contact center enterprise software that forced presenteeism upon the negotiators. Based on our findings, we discuss the relationship between ICT deployment, enforced presenteeism, and its instrumental and humanistic outcomes. We contribute to the IS literature on technostress by demonstrating how IS design and organizational support may not only alleviate employees' technostress but to turn the sources of technostress into sources of employee wellbeing and empowerment.

We proceed as follows. After this introduction, we review the relevant literature on technostress and coping. Then, we present our methodological choices and report on the findings of our empirical study. Finally, we discuss our findings and draw conclusions.

\section{Literature review}

\subsection{Stress and technology}

Stress, an uncomfortable emotional experience related to elements such as fear, dread, anxiety, irritation, sadness, and depression [26], is a common feeling among humans. In work life, stress among employees has become a growing concern for many organizations due to its negative impacts on workers' health [32] and work performance [1, 26]. Stress has been suggested to stem from a lack of congruence between a person (e.g., individual characteristics and abilities) and one's environment (e.g., work tasks, physical space, social situations) [12, 38]. The emergence of stressors may then lead into strain, i.e., individual's psychological and physiological response to stress, materializing as mood disturbances, dissatisfaction, or various physical symptoms [2, 38]. The rapid proliferation of ICTs has altered work environments, giving rise to technology as a source of stress, thus the term "technostress" [43].

Technology's characteristics may contribute to stressors in different ways. For example, usability features (usefulness, complexity, reliability) may contribute to work overload if the technology does not work properly or the workers find it difficult to use [2]. Rapid pace of technological change further aggravates work overload as it poses demands to workers' learning and skill acquisition, simultaneously effecting role ambiguity and job insecurity [2, 39]. However, perhaps most distinctive stress-inducing features of today's ICTs are intrusive in nature. For instance, ICTs' ability to monitor workers' activities decreases their perceived anonymity, causing feelings of invasion of privacy [2]. Still, the most prominent intrusive feature noted in the literature is presenteeism [2]. Presenteeism promotes an "always on" culture [5] as it increases demands on workers' availability and responsiveness $[2,8,10]$. This subjects workers to information overload (the negative impact of excessive amount of information on performance [13]), which has been found to cause loss of control and critical evaluation $[3,36]$, along with other negative effects.

Thus, as ICTs have caused the cost and effort of communication to plummet, they have brought about new kinds of workloads that end up taking a lion's share of workers' time. The accumulation of unaddressed emails and customer contacts has become a well-known issue in organizations along with unforeseen or additional tasks that may cause overwhelming interruptions to work [16] and prolong workdays [15]. Accordingly, presenteeism has been found to contribute to experienced work-home conflict, work overload, role ambiguity, and invasion of privacy [2, 39].

\subsection{Mitigating technostress}

Preventing the negative effects of presenteeism is important for organizations wishing to maintain a healthy work environment. It is well known that overcoming stress requires coping $[6,20]$, and workers have been found to cope with technostress in various ways [9, 30]. A coping process starts with an appraisal of the change (threat or opportunity), followed by an adaptation strategy aimed to mitigate the threat or make the most of the opportunity [4, 21], e.g., engagement (i.e., modification of stressful situation by eliminating or altering stressor) or disengagement (i.e., providing distraction from a stressor) [28]. 
When deploying ICTs, organizations can provide support to workers coping with stress or strain. These include encouraging knowledge sharing and collaboration, providing adequate technical support to users, and facilitating employees' involvement in the ICT change [31, 42]. Considering that one's anticipation of the fit between oneself and the environment (i.e., the new ICT) may influence the experienced strain [12], it can be important for organizations to influence employees' anticipation prior to the change. It has also been suggested that IS design features could mitigate technostress, but this remains largely an uncharted research area [40].

Despite the prominence of enforced and thus involuntary ICT-enabled presenteeism in organizations, most of prior research has concentrated on presenteeism in voluntary contexts, such as on leisure time or in voluntary telework. Moreover, little is known how organizations may mitigate technostress when deploying such involuntary ICT-enabled presenteeism.

\section{Methodology}

Since our study aims to improve understanding on human perceptions related to technological change in pre- and post-change settings, we took an interpretive approach. Gaining a rich understanding of both technical and social aspects of ICT-enabled change can be achieved through tapping into people's subjective perceptions and experiences. Therefore, we deem qualitative case study as an appropriate method for this study. As such, we collected qualitative data via interviewing employees who were to become exposed to technological change involving ICT-enabled, enforced presenteeism. To gain deep insights and to control for the effects of technology and organizational settings, we conducted our study in a single organization. Whereas we kept our minds open for the emergence of novel insights, we did not enter the field with an empty mind [37]. Rather, we informed ourselves about current literature's understanding of technostress, using the existing concepts as sensitizing devices [19].

\subsection{Case selection}

As the study aims to identify factors that affect individuals' perceptions - including expectations and experiences - in the beginning and at the end of technological change, the empirical part of the study utilizes purposeful sampling to find a relevant, information-rich empirical setting [29]. To identify such a case, the following criteria were used. First, the case organization should undergo a technological change which would expose its employees to involuntary presenteeism. Second, the subjects of the change should be individual employees who are knowledge workers. Third, to identify how perceptions evolve during the change, the data gathering should occur in two distinct points of time, preferably in the beginning when the change occurs and after it has been in action so that the employees have gained experiences. Based on these criteria for choosing an information rich case, a technological change pilot occurring in a bank was selected as the subject for the case study.

In fall 2018, a bank operating in Finland initiated an organizational change aimed to make its financial negotiator employees more accessible to customers. Thus far, financial negotiators had not had their direct phone numbers available for customers, but instead customers had to use other communication channels such as email or secure mail when contacting specific employees. An alternative option was to call a general service line in which a service representative in a centralized contact center received the call and manually added a callback task for the specific employee at the branch, which could often take more than a day before the task information reached the financial negotiator.

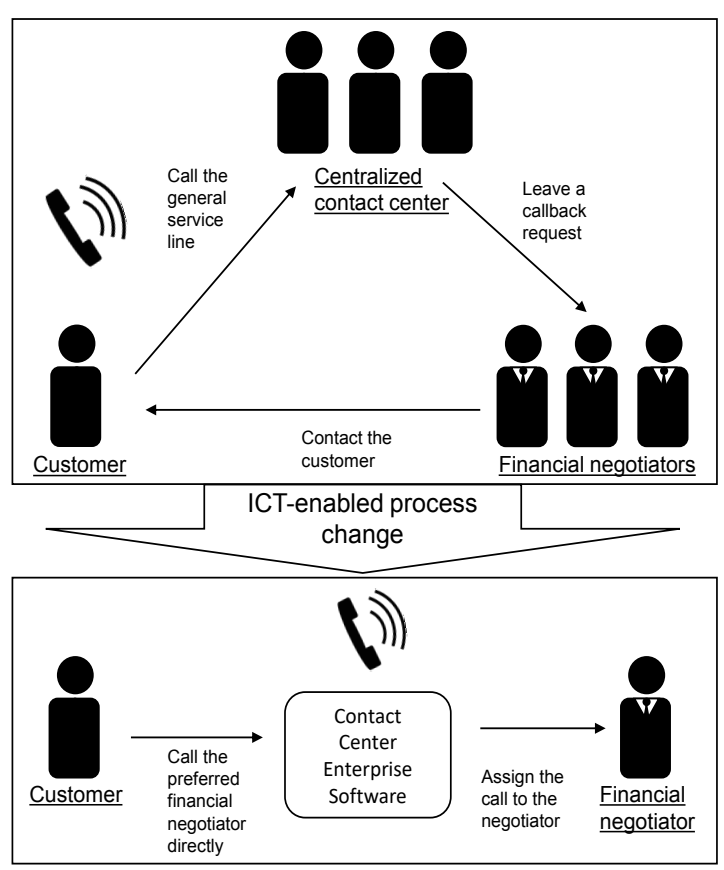

Figure 1. ICT-enabled process change

Therefore, the objective of the process change was to enhance the bank's service quality by providing the customers a more direct access to personal service (see Figure 1). This was achieved through the 
implementation of a new contact center enterprise software that enabled customers to directly reach the bank's financial negotiators via phone as well as to leave callback requests directly into the system.

However, the increased presenteeism was to be conducted so that it did not hinder the practice of workers' daily tasks, meetings, and assignments. To help workers manage their tasks, the software's key features included an ability to choose an availability status for calls (i.e., when to be available for direct calls or handling of callbacks), an automated callback queue listing (i.e., to see and execute on list of unhandled callback tasks), and callback rescheduling (i.e., to schedule specific times for call executions). The release also included many other features such as a survey tool, which the employees would fill after each customer call to report data about customer interaction.

\subsection{Data collection}

We collected longitudinal data through semistructured theme interviews with ten financial negotiators who were participating in the pilot (see Table 1 below). To capture the evolution of workers' responses to technological change, each informant was interviewed twice: in the beginning and at the end of the pilot. The pilot's kick-off event was held on November 5 when the new process and software were introduced to the participating employees.

Table 1. List of interviews

\begin{tabular}{|l|l|l|l|l|}
\hline $\begin{array}{l}\text { Inter- } \\
\text { viewee }\end{array}$ & $\begin{array}{l}1^{\text {st }} \\
\text { interview } \\
\text { date }\end{array}$ & $\begin{array}{l}1^{\text {st }} \\
\text { interview } \\
\text { length } \\
\text { (minutes) }\end{array}$ & $\begin{array}{l}2^{\text {nd }} \\
\text { interview } \\
\text { date }\end{array}$ & $\begin{array}{l}2^{\text {nd }} \\
\text { interview } \\
\text { length } \\
\text { (minutes) }\end{array}$ \\
\hline Alexandra & 5.11 .2018 & $44: 56$ & 13.12 .2018 & $44: 16$ \\
\hline Beth & 6.11 .2018 & $59: 10$ & 12.12 .2018 & $51: 23$ \\
\hline Arthur & 6.11 .2018 & $57: 27$ & 11.12 .2018 & $54: 36$ \\
\hline Caroline & 6.11 .2018 & $58: 45$ & 11.12 .2018 & $61: 46$ \\
\hline Diana & 6.11 .2018 & $55: 15$ & 11.12 .2018 & $54: 37$ \\
\hline Elena & 6.11 .2018 & $51: 42$ & 14.12 .2018 & $40: 00$ \\
\hline Fiona & 7.11 .2018 & $51: 02$ & 17.12 .2018 & $41: 12$ \\
\hline Gina & 7.11 .2018 & $51: 17$ & 18.12 .2018 & $57: 02$ \\
\hline Helena & 7.11 .2018 & $55: 19$ & 13.12 .2018 & $38: 31$ \\
\hline Ida & 7.11 .2018 & $43: 22$ & 12.12 .2018 & $38: 02$ \\
\hline
\end{tabular}

The first round of interviews was conducted in November 2018 to gather data of the expectations that the individuals had formed about the change after learning about it in the kick-off event. The interview topics and questions were formed based on the initial discussions that happened between the researcher and managers organizing the deployment as well as by utilizing the kick-off materials that were used to introduce the pilot for the employees. Therefore, the first-round interviews focused on the informants' current roles, work content, and routines; on their perceptions and understanding of the change; and on its expected impacts on their work. Although specific questions were used under each topic, the interviews aimed to encourage interviewees to bring up and discuss their own perceptions and topics, therefore requiring the interviewer to ask many follow-up questions to uncover the "why", "how", and "so what" aspects of the issues that interviewees brought up.

The second round of interviews was then conducted in December 2018 to collect data about the experiences and changes in expectations among the interviewees. The interview topics and questions were designed based on the first-round interview questions and initial insights that were derived from the analysis of the firstround interviews. Therefore, the second-round interviews focused on the experienced impacts of the process change and the contact center enterprise software, on the perceptions of the pilot, and on the perceptions of the technological change in general.

\subsection{Data analysis}

The data was analyzed using three coding techniques: 1) open coding, 2) axial coding, and 3) selective coding. Firstly, the study used open coding to identify ideas, events and incidents that characterize initial concepts about the research setting. For instance, we coded excerpts that related to presenteeism, stress, and information overload. This was done by reading the interview transcripts one at a time and in parallel to handle the open coding on a concept-level. These initial concepts were then grouped and regrouped to form concept categories. Secondly, axial coding was used to identify relationships between the concept categories generated by the open coding. This was done by looking for meaningful relationships between the concept categories and verifying them by checking that the uncovered relationships related to data from multiple interviewees. Thirdly, selective coding was used to integrate the concept categories to build theoretical relationships. This part of the analysis considered both the identified relationships between the categories as well as different concept group levels.

\section{Findings}

We find that several sources of technostress were weighing our interviewees prior to the technological 
change. Even pre-perceptions and expectations seemed to trigger experiences of stress already before the source of stress, i.e., the technological change, was implemented. Yet, the fears of enforced presenteeism proved largely unwarranted, as the stress never really translated into strain. It turned out that the presenteeism-enabling features in the new software not only solved the problems the bank was having with their customer service process, but also acted as stress reducing factors. Next, we identify the sources of technostress prior to the ICT implementation. Then, we report on our findings on the outcomes of the ICT implementation, organized into a discussion of instrumental outcomes and humanistic outcomes, respectively.

\subsection{Pre-deployment anticipations of technostress}

Overall, the levels of technostress were high and presenteeism-related stressors identified in prior literature [2] were prevalent among our interviewees after the announcement of the planned software deployment (see Figure 2). In particular, the employees were concerned of work overload, invasion of privacy, and information overload.

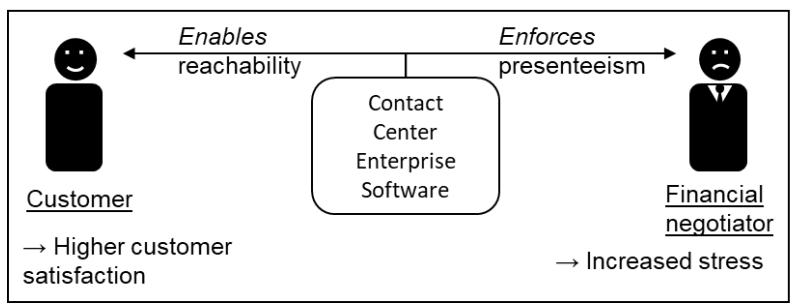

Figure 2. Pre-deployment anticipations of technostress

4.1.1. Work overload. Workload denotes both the quantifiable amount of work that an individual must do as well as their perception of difficulty that is associated with the work. Therefore, work overload occurs if the quantity or difficulty of work is perceived to exceed one's capacity. Most of the interviewees felt that their work schedules were already very full of tasks and finding enough time for handling direct calls and callback requests was difficult.

Caroline: This calendar management is sometimes so damn difficult, although [management] says that you control your own calendar. But there are requests [for additional work] coming all the time from other people.

Moreover, some of the interviewees pointed out that their workdays tend to have a lot of unpredictability in terms of upcoming scheduled customer negotiations.

Beth: The workday is scattered in a way that you cannot say in the morning when you come to work that you have the whole day for something you have planned to do, but instead there are many [unexpected] fragments within the single day.

The upcoming enforced presenteeism was perceived to aggravate this problem. Whereas before there had been at least some buffers between the negotiators and their customers, the former ones feared that enabling direct reachability would create an uncontrollable surge of customer contacts, resulting in increasingly chaotic work overload. Indeed, the interviewees noted that the initiated technological and process changes contributed towards increased unpredictability as direct customer contacts could now arrive in uncertain quantities at any time. Moreover, having to learn to use a new technology was seen to further increase the workload.

Gina: Our calendars are already full and then we should fit these [calls] somewhere in-between [the meetings]. As there are such high requirements for the amount of customer meetings, it makes me feel that if I would like to schedule some time to learn these new systems and instructions...there is always something urgent to do, so I end up postponing the learning.

Beth: [There have been] situations that you were not even aware about the upcoming change. So maybe there was something about it on the intranet, well has one noticed it in the middle of all the hassle? So sometimes, you are using software and then you are like "What? This has completely changed! What should I do?" Then the discussions among colleagues starts where people are asking each other "have you noticed this?"

One interviewee pointed out that an individual's personality can amplify the experienced stress from work overload.

Beth: When there is too much [technological change] it causes stress and I myself feel that since I am quite pedantic as a person and [the change] causes stress in a way that my performance-oriented attitude creates a pressure to do things the right way or to use the software correctly, so it generates the rat race.

4.1.3. Invasion of privacy. The possibility that managers could use the new software to monitor an individual employee's call performance and general work activity (i.e., time spent on available-status or call handling quantities) caused stress among the negotiators. While the software itself merely enabled presenteeism, its monitoring features presented managers a concrete tool to enforce it. The negotiators 
were concerned that such management surveillance would invade their privacy at work.

Caroline: I get stressed about the feeling that someone somewhere is monitoring that this one person does not have her phone open, but I don't always have the chance to do that... So, if [the software] creates this type of monitoring, it is really terrible.

4.1.2. Information overload. Concerns of information overload were tightly connected to specific features of the presenteeism-enabling software: increasing information quantity, poor information quality, and rapid pace of new information supply. The quantity of information (e.g., regulatory and management enforced instructions) hinders an individual's ability to remember it and to understand it in context as well as to utilize it in decision-making. The new software added more information to the process and allowed the extraction of new information, thereby requiring also the negotiators to digest and produce more information from their work than before. For instance, in the new operating model the negotiators would be required to fill in data about the customer interaction after each phone call. Moreover, the negotiators were now obligated to record additional customer data required by the law (e.g., political contacts) into yet another system. All this was seen to aggravate complexity in itself but was further complicated by the need to utilize different systems. As the software posed involuntary presenteeism upon its users, the negotiators were especially stressed about their ability to cope with the increasing amount of information it entailed, as being directly reachable to customers would force them to collect and use new information.

Interviewer: Is it so that when everything [in terms of operations] becomes more complex [as you mentioned with regards to enterprise software], it is caused by the overload of information that needs to be internalized?

Alexandra: Well it is that and then there are also other things that require memorizing, such as what [information] needs to be recorded to which [software] system as those are [often] based on regulations and mandatory instructions, so yes, there is a lot to be remembered.

Furthermore, also the quality of information (e.g., storage, format and understandability) was concerning the negotiators. The pre-perceptions showed strong obscurity towards knowing what support infrastructure is available and how it can be utilized.

Arthur: It is always necessary to study all instructions again, to ask some colleague who has recently done a similar thing, or to call help desk for advice. Hence, this kind of double-checking [is frustrating] when you are not entirely sure how things are supposed to be. And the instructions are such that you perceive that a procedure can be done this way, but it could also be done in another way.

In addition, the feeling of not having enough time to digest the information regarding changes was seen as a source of stress. The interviewees reported significant anxiety stemming from the rapid pace of operational changes at their workplace. A major part of this stress specifically related to the technological aspect of change, as it was seen to increase the hecticness in their work environment, causing frustration and confusion.

Fiona: Technologies and software are changing so blindingly [fast] here that when you are [for example] on a one-month holiday [and come back] instructions and others have changed, and new things have appeared. So yes, this [technological change] proceeds all the time.

\subsection{Instrumental outcomes of ICT deployment}

From the technical perspective, the new pilot was a success. The management's instrumental objectives of the change were achieved as the new software and the operating model fixed some fundamental problems in the bank's service process through better reachability.

Gina: Well, we have received countless number of negative feedbacks for years, because of our [poor] reachability. We have always had to tell [the customers] that we unfortunately cannot answer because the current [software] system does not enable it, but now we can tell the customers that this has changed for the better.

Beth: There have been commendations coming from local real estate agents. For example, one man was amazed as he told me how difficult it has been to reach these people [financing negotiators] and admired the fact that we are returning to a world where it is possible to reach people.

\subsection{Humanistic outcomes of ICT deployment}

Despite the apparent fears and anxieties expressed by the interviewees prior to the technological change, the reality turned out quite different. The employees' concerns ended up being largely unwarranted as the newly deployed software and process changes it entailed neither resulted in ICT-induced chaos and stress nor did it create a matrix of Orwellian surveillance. In fact, the opposite was true: while solving the problems in the bank's customer service process, the new ICT had mostly a decreasing impact on the employees' stress levels and it in fact empowered them. Such stress reducers included increased customer satisfaction, reduced workload, 
ability to control one's availability for calls, the fairness-inducing effect of monitoring, and a sense of empowerment.

4.3.1. Customer satisfaction as stress reducer. Before the pilot, customers had major difficulties to reach the financing negotiators, which resulted in customer dissatisfaction and hence hindered the ambience of customer interactions in the employees' daily work. Therefore, the negotiators felt content with the rising customer satisfaction levels.

Fiona: ...it is always so horrible to listen to those [feedbacks] where [customers] tell how they have been listening half an hour some sort of unpleasant music [while queuing]. I just feel bad on behalf of the customers, and on the other hand, I myself prefer that the customers would reach me faster if I have an open case with them, so that they would not be bounced between multiple channels. Hence, I feel that this [change] is a very good improvement.

However, contrary to what the employees had feared, this process improvement did not come at the expense of their work wellbeing. It turned out that the improved reachability enabled by the software entailed significant reductions in stress through increased customer satisfaction.

Gina: Probably it has removed stress because we have had quite a lot of stress because customers have not been able to reach us... or maybe I can't say that it has removed stress, but it has reduced it. [...] ...for years our reachability has been such a bad problem. The fact that customers get used to this [new operational model] will ease things quite a lot.

Diana: Now that I receive that positive [customer] feedback, it of course influences my job performance [positively] and I can even be a little bit proud of that.

4.3.2. Reduced workload as stress reducer. By the end of the pilot, expected usefulness impacts from both technological and process changes were observed, as employees' stance towards the change strengthened due to the positive experiences.

Arthur: ...it makes it easier to contact customers and the reason why it makes this easier and why it makes my work feel more rational is that there is less back and forth calling.

Caroline: I believe that it has significantly improved my work. It has eased and improved [tasks] as certain functionalities such as saving numbers to the system among others, have made my daily work practices much easier.

4.3.3. Transparency as stress reducer. Even the threat of surveillance that evoked deep concerns among the negotiators prior to the change turned out to have a bright side in the end. Instead of experiencing invasion of privacy, the negotiators found the new software increasing transparency in the distribution of work and thereby positively contributed to their sense of fairness.

Arthur: [Monitoring] is good in the sense that it makes things fair. Sometimes there are days when there are no moments to be anywhere else than client meetings, so it is possible [and ok] to see [low availability statistics], but if you are offline all the time, although you have a chance to be available, it is not fair for others. So, in my opinion it is fair that there is possibility to monitor [the software use performance].

4.3.4. Empowerment as stress reducer. The fact that the new software enabled the negotiators to be directly reachable to customers and that it gave them control over the reachability resulted in a sense of empowerment. The new affordances allowed the negotiators to make promises to customers with stronger confidence than before, making them feel empowered as they were no longer constrained by the old process and technology.

Diana: ... and I can even be proud about the fact that I can say [to my customers] "hey, now you can reach us, as we have this unresolved issue, by just calling this [direct] number and if I don't answer right away then I will reach back to you as soon as possible". Therefore, now that I can give the customer a verbal promise that I operate in this way, and the software enables it and ensures that I actually do things in this manner.

4.3.5. Managerial intervention as stress reducer. The new software in itself did not completely eliminate stress, as some still found using it as challenging.

Beth: The only stress I have experienced, and which has been also discussed in morning meetings is that [using the software] is very challenging as it needs to be frequently reopened and it causes frustration.

Although most interviewees did not experience major need for management support in using the software, it was not apparent for them that such support would have been available. Therefore, the lack of awareness of support availability in the beginning could have potentially escalated into harmful outcomes later during the pilot if there would have been strong and immediate need to utilize support resources. Fortunately, these needs emerged only toward the end of the pilot, resulting in a managerial intervention. This intervention encompassed the organizing of technical training sessions aimed to ensure that everyone had the software's use under control. This helped to counter technostress stemming from an inability to master the new software. 


\section{Discussion}

ICTs are increasingly reshaping modern workplaces and therefore also an increasing share of stress stems from technologies [24] that may produce negative effects like interruptions and increasing workloads [16]. Such stressors may cause psychological responses that manifest as mood disturbances and worsened job satisfaction [38]. This has resulted in calls for IS research to reach beyond the simplistic assumption that successful IS implementation would always lead to positive effects, turning the spotlight on the complexifying effect of technostress [2, 31, 43]. Especially presenteeism that some ICTs entail has been found to be a major source of stress [2]. While exploring this dark side of IS use, we shed new light on the relationship between technology and its outcomes. Specifically, our case study demonstrates that sources of technostress may not automatically lead to experienced strain, even if they are present in the IS that is being implemented. Rather, the strain appears to depend on the functional affordances of the IS (i.e., potential uses that originate from the properties of IS and determine what a user can do with the IS [25]) and what the implementing organization (i.e., managers) does with those affordances. Figure 3 illustrates the stress-decreasing effect of ICT affordances found in our case study.

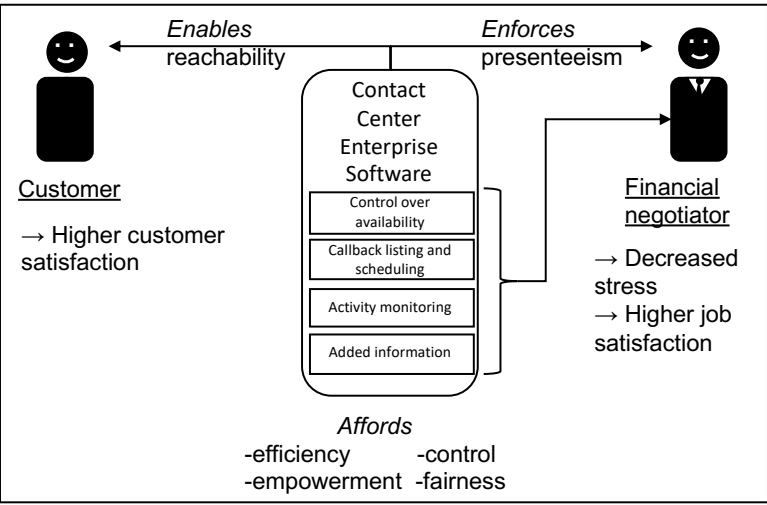

Figure 3. Using ICT affordances to mitigate technostress

We show that while the introduction of enforced presenteeism via ICT implementation does cause employees to stress, this potentially harrowing effect can be turned around through intelligent design and management of the technology. Answering the recent call for research on stress-reducing IS design features [40], we find that stress can be mitigated through specific affordances, to the extent that the very features that were found to produce stress actually turn into positive experiences like a sense of fairness and empowerment. Certain stress-inducing qualities of presenteeism were negated with stress-reducing features in the new software. For instance, while the negotiators had to be directly reachable to customers, they were given control mechanisms over their availability, allowing them to take callbacks in case they were busy with other things when a customer called. This not only improved customer service but also created a sense of empowerment to the employees.

Interestingly, many of the stress reducers found in the data are directly connected to the instrumental outcomes of ICT implementation. Increased customer satisfaction, more efficient work processes, and higher transparency all represent outcomes that tend to lead to lower costs, higher profits and, especially in the case of ICT, increased organizational control [27]. They are therefore typically desirable from the managerial perspective, but due to their instrumental focus, they may not necessarily always be in the interests of employees. Yet, in our case company these instrumental outcomes worked in synergy with humanistic outcomes of job satisfaction and decreased stress at workplace. The stress-inducing factors turned out to be multifaceted, having a stress-reducing side in them. This stress-reducing aspect of the technology was successfully harnessed by the implementing organization, leading into lower stress among employees than before. Therefore, the technology simultaneously addressed technical and social strains present in the organization. This suggests that instrumental and humanistic goals of technology implementation do not need to be mutually exclusive or represent tradeoffs.

Prior to the change, some informants felt as if their cognitive capacity to handle the surge of new information was not sufficient under enforced presenteeism, hence causing fears of losing control. Earlier literature has identified similar symptoms such as omission of information [11] and loss of control and critical evaluation [3, 36] when facing information overload. Indeed, information overload is described as a real and severe risk for organizational performance, as it may cause employees to become less focused, hindering their productivity [33]. While organizations could mitigate stress through various interventions [28], we highlight the potential of using IS affordances to manage stress. This may produce also inherently humanistic outcomes such as employee empowerment and satisfaction.

\section{Conclusions and further research}

Previous research has focused on individual coping with technostress and organizational mitigation mechanisms [e.g., 9, 30, 31, 42]. Our focus has been on 
IS design features that mitigate stress and empower employees [40], their organizational implementation, and the resulting instrumental and humanistic outcomes. This study makes several theoretical contributions in the intersection of sociotechnical change and technostress by providing rich descriptions of employees facing technological change that is poised to lead to higher levels of presenteeism. First, we propose that stress-inducing ICTs may have stressreducing sides to them, pointing towards the multifaceted nature of presenteeism's stress factors. Second, to our best knowledge, this study is the first empirical study to specifically shed light on the effects of ICT-enabled involuntary presenteeism. Our research setting is also unique in the sense that we study the effects of presenteeism longitudinally by tapping into employees' perceptions before and after a technological change. This allowed us to contrast the technostress experienced prior to the change with the actual experience of potential strain due to the newly implemented ICT, enabling us to make conclusions about the development of technostress over time. Third, this study provides useful insights and tools for business practitioners who have responsibilities to plan and lead technological change deployments. Recognizing both stress increasing and stress reducing potential in technology's affordances can provide direction for managers when aiming for dual optimization of instrumental and social goals of technology.

The limitations of the study relate mostly to the specificity of the change deployment observed, the number of informants, and the observation of only one organization in the empirical research setting. Hence, studying involuntary presenteeism in different types of change deployments or having more variety in terms of the amount of change recipients or their organizational roles could potentially reveal new factors that have an impact on individuals' cognitions on technological change. Another potential limitation is that although the study observed change initiative in its beginning and the end, the observed empirical setting was relatively short so it does not correspond to a longitudinal study that could validate more causal effects. Hence, the results of the study may only indicate what kind of dimensions could be considered in quantitative studies on technological change.

\section{References}

[1] Ahuja, and Thatcher, "Moving beyond Intentions and toward the Theory of Trying: Effects of Work Environment and Gender on Post-Adoption Information Technology Use", MIS Quarterly 29(3), 2005, pp. 427-459.

[2] Ayyagari, Grover, and Purvis, "Technostress:
Technological Antecedents and Implications", MIS Quarterly 35(4), 2011, pp. 831-858.

[3] Bawden, D., and L. Robinson, "The dark side of information: Overload, anxiety and other paradoxes and pathologies", Journal of Information Science 35(2), 2009, pp. 180-191.

[4] Beaudry, A., and A. Pinsonneault, "Understanding User Responses to Information Technology: A Coping Model of User Adaptation”, MIS Quarterly 29(3), 2005, pp. 493-524.

[5] Belton, P., "Is tech addiction making us far more stressed at work?", BBC News, 2016.

https://www.bbc.com/news/business-36517644

[6] Caplan, R.D., "Person-Environment Fit Theory and Organizations: Commensurate Dimensions, Time Perspectives, and Mechanisms", Journal of Vocational Behavior 31(1), 1987, pp. 248-267.

[7] Cascio, W., and J.R. Montealegre, "How Technology is Changing Work and Organizations", Annual Review of Organizational Psychology and Organizational Behavior 3, 2016, pp. 349-375.

[8] Chesley, N., "Information and communication technology use, work intensification and employee strain and distress", Work, Employment and Society 28(4), 2014, pp. 589-610.

[9] D’Arcy, J., T. Herath, and M.K. Shoss, “Understanding Employee Responses to Stressful Information Security Requirements: A Coping Perspective", Journal of Management Information Systems 31(2), 2014, pp. 285-318.

[10] Davis, G.B., "Anytime/anyplace computing and the future of knowledge work", Communications of the ACM 45(12), 2002, pp. 67-73.

[11] Edmunds, A., and A. Morris, "Problem of information overload in business organizations: A review of the literature", International Journal of Information Management 20(1), 2000, pp. 17-28.

[12] Edwards, J.R., Robert D. Caplan, and R. Van Harrison, "Person-Environment Fit Theory: Conceptual Foundations, Empirical Evidence, and Directions for Future Research", In Theories of organizational stress. Oxford: Oxford University Press, 1998, 28-67.

[13] Eppler, M.J., and J. Mengis, “The concept of information overload: A review of literature from organization science, accounting, marketing, MIS, and related disciplines", Information Society 20(5), 2004, pp. $325-344$.

[14] Ferneley, E., and P. Sobreperez, "Resist, comply or workaround? An examination of different facets of user engagement with information systems", European Journal of Information Systems 15(4), 2006, pp. 345-356.

[15] Filcher, A., "Employees working longer hours due to technology", HRreview, 2015.

https://www.hrreview.co.uk/hr-news/strategynews/employees-working-longer-hours-duetechnology/58524 
[16] Ter Hoeven, C.L., W. van Zoonen, and K.L. Fonner, "The practical paradox of technology: The influence of communication technology use on employee burnout and engagement", Communication Monographs 83(2), 2016, pp. 239-263.

[17] Johns, G., "Presenteeism in the workplace: A review and research agenda", Journal of Organizational Behavior 31(4), 2010, pp. 519-542.

[18] Joyce, C., J. Fisher, J. Guszcza, and S.K. Hogan, Positive technology. Designing work environments for digital well-being, 2018.

[19] Klein, H.K., and M.D. Myers, “A Set of Principles for Conducting and Evaluating Interpretive Field Studies in Information Systems", MIS Quarterly 23(1), 1999, pp. 6793.

[20] Lazarus, R.S., and S. Folkman, Stress, Appraisal, and Coping, NY: Springer, New York, 1984.

[21] Lei, C.F., and E.W.T. Ngai, "The double-edged nature of technostress on work performance: A research model and research agenda", 35th International Conference on Information Systems "Building a Better World Through Information Systems”, ICIS 2014, 2014, pp. 1-18.

[22] Maier, C., S. Laumer, C. Weinert, and T. Weitzel, "The effects of technostress and switching stress on discontinued use of social networking services: a study of Facebook use", Information Systems Journal 25(3), 2015, pp. 275-308.

[23] Mankins, M., "Is Technology Really Helping Us Get More Done?", Harvard Business Review, 2016, pp. 1-5.

[24] Markus, M.L., "Technochange Management: Using IT to Drive Organizational Change", Journal of Information Technology 19(1), 2004, pp. 4-20.

[25] Markus, M.L., and M. Silver, “A Foundation for the Study of IT Effects: A New Look at DeSanctis and Poole's Concepts of Structural Features and Spirit", Journal of the Association for Information Systems 9(10), 2018, pp. 609632 .

[26] Motowidlo, S.J., J.S. Packard, and M.R. Manning, "Occupational Stress. Its Causes and Consequences for Job Performance", Journal of Applied Psychology 71(4), 1986, pp. 618-629.

[27] Orlikowski, W.J., "Integrated information environment or matrix of control? The contradictory implications of information technology", Accounting, Management and Information Technologies 1(1), 1991, pp. 9-42.

[28] Ortiz de Guinea, A., and J. Webster, “An Investigation of Information Systems Use Patterns: Technological Events as Triggers, the Effect of Time, and Consequences for Performance", MIS Quarterly 37(4), 2013, pp. 1165-1188.

[29] Patton, M., "Qualitative Evaluation and Research Methods", Qualitative Evaluation and Research Methods, 1990, pp. 169-186.

[30] Pirkkalainen, H., M. Makkonen, M. Salo, and M. Tarafdar, "Coping with Technostress: When Emotional
Responses Fail", Proceedings the 38th International Conference on Information Systems, (2017), 1-17.

[31] Ragu-Nathan, T.S., M. Tarafdar, B.S. Ragu-Nathan, and $\mathrm{Q}$. Tu, "The consequences of technostress for end users in organizations: Conceptual development and validation", Information Systems Research 19(4), 2008, pp. 417-433.

[32] Richardson, K.M., and H.R. Rothstein, "Effects of Occupational Stress Management Intervention Programs: A Meta-Analysis", Journal of Occupational Health Psychology 3(1), 2008, pp. 69-93.

[33] Ruff, J., "Information overload: causes, symptoms and solutions", Harvard Graduate School of Education, 2002.

[34] Salo, M., H. Pirkkalainen, M. Makkonen, and R. Hekkala, "Distress, Eustress, or No Stress? : Explaining Smartphone Users ${ }^{\mathrm{TM}}$ Different Technostress Responses", Proceedings the 39th International Conference on Information Systems, 2018, pp. 1-17.

[35] Sarker, S., S. Chatterjee, X. Xiao, and A. Elbanna, "The Sociotechnical Axis of Cohesion for the IS Discipline: Its Historical Legacy and its Continued Relevance", MIS Quarterly 43(3), 2019, pp. 695-719.

[36] Schick, A.G., L.A. Gordon, and S. Haka, "Information overload: A temporal approach", Accounting, Organizations and Society 15(3), 1990, pp. 199-220.

[37] Siggelkow, N., "Persuasion with Case Studies", Academy of Management Journal 50(1), 2007, pp. 20-24.

[38] Smith, M.J., F.T. Conway, and B.-T. Karsh, "Occupational Stress in Human Computer Interaction", Industrial Health 37(2), 1999, pp. 157-173.

[39] Suh, A., and J. Lee, “Understanding teleworkers' technostress and its influence on job satisfaction", Internet Research 27(1), 2017, pp. 140-159.

[40] Tarafdar, M., C.L. Cooper, and J.F. Stich, "The technostress trifecta - techno eustress, techno distress and design: Theoretical directions and an agenda for research", Information Systems Journal, 29(6) 2017, pp. 6-42.

[41] Tarafdar, M., A. Gupta, and O. Turel, "Special issue on 'dark side of information technology use': An introduction and a frame- work for research", Information Systems Journal 25(3), 2015, pp. 161-170.

[42] Tarafdar, M., E.B. Pullins, and T.S. Ragu-Nathan, "Technostress: Negative effect on performance and possible mitigations", Information Systems Journal 25(2), 2015, pp. $103-132$.

[43] Tarafdar, M., Q. Tu, B.S. Ragu-Nathan, and T.S. RaguNathan, "The Impact of Technostress on Role Stress and Productivity", Journal of Management Information Systems 24(1), 2007, pp. 301-328.

[44] Wang, K., Q. Shu, and Q. Tu, “Technostress under different organizational environments: An empirical investigation", Computers in Human Behavior 24(6), 2008, pp. 3002-3013. 